The structure of human trafficking:

Lifting the bonnet on a Nigerian transnational network

\author{
Paolo Campana \\ Institute of Criminology \\ University of Cambridge
}

Version submitted for publication in the British Journal of Criminology Accepted on 27.03.2015

Author's contact details:

Institute of Criminology, University of Cambridge

Sidgwick Avenue, Cambridge CB3 9DA

United Kingdom

Email: pc524@cam.ac.uk 


\section{The structure of human trafficking: Lifting the bonnet on a Nigerian transnational network}

Contrary to widespread belief, human trafficking operations are characterised by significant costs, particularly monitoring costs, and diseconomies of scale. How do traffickers achieve high capacity in their operations? This paper is an empirical in-depth study of the structure and activities of a large-scale human trafficking ring operating between Nigeria and Europe. It is based on a set of novel data sets that was manually coded and analysed using network analysis techniques, and shows that high trafficking capacity is associated with a high level of externalisation of activities. Offenders mostly act as independent agents, in a similar way to contractors. The trafficking ring does not appear to be run along ethnic or family lines, but what does emerge is a rather clear division of labour and role specialisation. Finally, the paper contributes to the broader debate on coordination in illegal settings and puts into question the idea that transnational crime is invariably best fought transnationally.

Keywords: human trafficking; transnational organised crime; network analysis; co-offending; coordination. 


\section{Introduction}

Human trafficking has received increasing global attention since the adoption in 2000 of the UN Protocol to Prevent, Suppress and Punish Trafficking in Persons (WHO 2012). Special rapporteurs have been appointed by various governments to improve their response to trafficking, while global campaigns have been launched by international organisations as well as advocacy groups to raise awareness and keep human trafficking at the top of the global agenda. Over the years, scholars have produced a great deal of research, exploring a variety of issues ranging from the definition of trafficking to its measurement and studying the impact on victims. ${ }^{1}$ While good progress has been made, there still remains a need to advance our understanding of the mechanisms underpinning the organisation of trafficking operations. Valuable insight has so far been gained through anecdotal evidence, often interviews with victims and police reports (see, for instance, Aronovitz 2001 and 2009; Turner and Kelly 2009; Triandafyllidou and Maroukis 2012; and Hales and Gelsthorpe 2012). The aim of this work is to expand on the existing literature by adopting a systematic and quantitative approach to the study of the structure of human trafficking. It will combine content analysis of court data and social network analysis techniques to empirically reconstruct patterns of coordination (i.e. cooffending) among traffickers.

This paper also offers a theoretical framework to interpret the determinants of coordination among traffickers; in addition, it estimates the extent of their impact in a real-word trafficking network. There is a tendency in the current literature to depict trafficking organisations as successful, trouble-free and experiencing no limits as regards their growth: traffickers are seen as quasi-omnipotent individuals able to reap almost unlimited profits from their illicit trade. This paper takes a different view, arguing that organisational costs and constraints play a major - but often neglected - role in shaping the structure of the organisations involved. This work will focus primarily on the monitoring costs borne by offenders. Understanding costs and constraints help gain a better knowledge as to how offenders can increase the 'trafficking capacity' of their operations (i.e. the volume of victims trafficked). Based on the evidence presented, the paper will also discuss a number of policy implications for combatting human trafficking both transnationally and domestically.

For the purpose of this work, human trafficking is viewed as an illegal trade in which the commodity exchanged is control over a person - in accordance with the definition set out in the 2000 UN Protocol Against Trafficking in Persons ${ }^{2}$. This definition of trafficking clearly sets it apart from smuggling (in the latter, the commodity traded is primarily the illegal entry into a 
country). As the remainder of the paper should make clear, the nature of the commodity traded has implications for the organisational arrangements adopted by the criminal organisations involved in the trade.

\section{Structure of the paper}

This paper proceeds as follows: Section 1 discusses the previous research on the structure of human trafficking and points to some relevant open questions. Section 2 sets out a theoretical framework to interpret coordination among traffickers, and spells out three distinct hypotheses on the organisation of trafficking operations that will then be put to the test. Section 3 discusses the data and methods for this study. Subsequently, Section 4 reconstructs the structure and activities of the trafficking ring under consideration using a network analysis approach. Section 5 offers an explanation of the structure observed by means of a regression technique specifically developed for network data. Finally, Section 6 concludes with a discussion of relevant policy implications.

\section{The organisation of human trafficking}

Salt and Stein (1997: 467) pioneered the study of human trafficking interpreted as an international business. In their paper, they explored the "systematic organisation" and modus operandi of the actors involved, and offered an analytical model of trafficking operations based on three consecutive stages: mobilization (i.e. recruitment in the country of origin); en route activities; and insertion into the destination country. They then spelled out the tasks that traffickers may carry out in each stage, and postulated the presence of a central management overseeing the process (Salt and Stein 1997: 490). According to Salt and Stein (1997: 476), the extent to which the central management actually controls all the stages is a function of the size of the organisation: the larger the organisation, the more likely it is that such an organisation

will "encompass all aspects of the model". They also noted that "centralized system of planning management may exist, particularly with large-scale organizations" (p. 476). Based on the SaltStein model, we should expect to observe more centralisation in trafficking activities as the size of an organisation increases.

Salt (2000: 43) cites evidence of hierarchical and centrally coordinated organisations operating in Poland before the country's accession to the European Union. Salt (2000: 43) describes the presence of a top-echelon able to coordinate the activities across countries: "at the top is a 'brain', a leadership that is thought to look after the entire route and its security. At the next 
level are found internationally linked 'Mafia' bosses in each country through which a route runs. Only those in the top two strata have direct international connections".

The involvement of transnational Mafia organisations in human trafficking has been cited by other authors. Vayrynen (2003: 19) claims that organised crime syndicates have rapidly become more internationalised and have started to strike agreements of mutual cooperation. These syndicates include the Italian mafias, and the Chinese triads, as well as the Russian, Nigerian and Albanian crime syndicates. According to Vayrynen (2003), their involvement in human trafficking includes the provision of fake documents, transport and accommodation in a destination country (see also Shannon 1999 and Caldwell et al. 1999). Crucially, this involvement may also extend to the control of victims during the exploitation stage, particularly in the sex industry. Crime syndicates are "ready to seize them [the victims] if there is an effort to escape" (Vayrynen 2003: 19). In Vayrynen's view, the Albanian and the Kosovar mafias control 70 per cent of massage parlours in the London neighbourhood of Soho "in which prostitutes are held as virtual slaves and are treated with increasing violence" (p. 19).

Aronowitz (2001) explores the organisational arrangements that human traffickers may adopt. These arrangements fall on a continuum ranging from individual traffickers with links to organised crime groups to "highly structured, criminal organisations controlling the trafficking process from start to finish" (p. 176). Aronowitz (2009) expands on her earlier work with the support of anecdotal evidence from a number of different countries / routes (see also Aronowitz et al. 2010, Ch. 2 and 5). She interprets trafficking as a process consisting of four stages (recruitment; transportation; exploitation; and criminal proceeds) and then identifies three broad categories of potential organisational arrangements (Aronowitz 2009: 66-69). These arrangements are ordered according to their increasing complexity. The first type is characterised by individual traffickers working independently (i.e. absence of organisation). The second type encompasses small groups of organised criminals. These groups show a small degree of specialisation and tend to be only involved in trafficking within a single country or some small-scale international trafficking. Finally, the third category includes large trafficking organisations:

At the end of the continuum are the highly structured, criminal organizations controlling the trafficking process and providing the full set of services (from recruitment, documentation forgery, transportation, corruption of police officials, where necessary, and exploitation) from start to finish. (Aronowitz 2009: 67). 
These large organisations are described as sophisticated entities composed of several subunits that specialise in a specific "part or sequence" of the trafficking operations. However, these subunits are overseen and coordinated by a central "management unit [that] maintains a vertical structure and has knowledge of and controls the other subunits" (Aronowitz 2009: 68). According to Aronowitz (2009: 68), "significant evidence points toward a high degree of organization and sophistication in trafficking operations". ${ }^{3}$

Shelley (2007) maintains that people often hold the erroneous belief that traffickers are only small-scale entrepreneurs. In reality, she argues, "many transnational trafficking organisations are large and traverse numerous continents" (p. 123). She also notes that traffickers appear to be involved in all stages of the process, including the control over victims during the exploitation stage: "the international links of the traffickers allow them to deploy violence at all stages of their network. Their ability to intimidate both the victim and the family at home differentiates contemporary trafficking from the slave trade of earlier centuries" (Shelley 2007: 132).

Triandafyllidou and Maroukis (2012: 184) maintain that in human trafficking networks middlelevel agents may or may not be involved in all legs of the journey; however, they all tend to be "in the criminal activity of abusing and exploiting their victims". Based on their fieldwork in Turkey, Içduygu and Toktas (2002) explore whether operations are systematically organised and centralised in a Mafia-like fashion or based on a looser network of relations. These networks are interpreted by Içduygu and Toktas as a function of ethnic and/or kin relationships (p. 35). Finally, they concluded that "generally speaking, independent individuals or groups specialized in particular aspects of the operation combine and coordinate their efforts at various stages" along the process (Içduygu and Toktas 2002: 49). Yet, despite their claim to explore both trafficking and smuggling operations, their evidence mostly concerns human smuggling, and it is unclear to what extent their findings can be applied to trafficking organisations.

In the case of Nigerian human trafficking, law enforcement officials interviewed by Okojie at al. (2003: 86) suggest that "trafficking is in the hands of organised crime groups". These groups may adopt different organisational structures, and some of them are described as "well structured, based on ethnic affiliations" (Okojie at al. 2003: 86). Nigerian trafficking rings are often considered to be able to control the entire trafficking process due to either ethnic or family ties (see, e.g., Mancuso 2014: 68). Triandafyllidou and Maroukis (2012: 184) cited Nigerian trafficking as a case in which "trafficking is carried out by mafia-style criminal gangs". Siegel and de Blank (2010: 443) explored the role played by the so-called 'madams' (i.e. female 
'pimps') within Nigerian trafficking groups, and conclude that "the 'madam' leads the criminal organisation and plans its activities. She gives orders to subordinates, coordinates the human trafficking, manages the prostitutes, and controls the finances". Madams can lead operations of "sizable, internationally operating organisation[s]" (Siegel and de Blank 2010: 443; see also Siegel 2012). Mancuso (2014: 82) explores the centrality of madams in Nigerian human trafficking networks, and deduces that some of them do indeed "manage the entire sex trafficking process by participating actively in all decision-making processes". This is mainly thanks to ethnic- and family-based connections. Other madams, however, appear to have a much more peripheral role in brokering links among participants in the trafficking operations.

In spite of these studies, a number of questions have still been left open. The first is to what degree we observe a centralised echelon in large-scale trafficking organisations, as claimed by Salt and Stein (1997). Secondly, it remains unclear exactly how coordination is achieved in large transnational networks. Previous research has not gone beyond describing the phenomenon, and has stopped short of addressing the question as to why traffickers adopt certain organisational arrangements and not others. This paper aims to offer an explanation of the structure of human trafficking that is both theoretically-informed and empirically-based.

\section{A framework to interpret coordination among traffickers}

Until now, the previous research on human trafficking has overlooked the constraints that large transnational networks may face. The assertion that human trafficking can generate almost unlimited profits as the repeated exploitation of victims carries virtually no costs has almost become a mantra. According to Shelley (2010: 89), human trafficking can generate a "continuous source of profit" for criminals (see also Hyland 2001: 38). Kandathil (2005: 91) maintains that victims "provide a flexible, inexpensive, virtually inexhaustible source of labour" (Kandathil 2005: 91). This view has also been supported by the US Department of State (2001: 1).

Instead of being a cost-free enterprise, the fact that victims can be exploited over prolonged periods of time generates a specific type of cost due to monitoring. So far, these costs have been largely overlooked by scholars, even by those who sought to offer an economic model to the study of trafficking (see, for instance, Wheaton et al. 2010).

Traffickers are indeed required to monitor their victims for extended periods, i.e. until the monetary conditions for releasing the victims are met. These periods can often be very long. In the case of Nigerian trafficking, the amount of money typically requested by exploiters ranges 
between $\$ 40,000$ and $\$ 70,000$ (Okojie et al. 2003: 7 and 68; Prina 2003: 21). This translates into victims being held captive for a minimum of one year to (often) three years or more (Prina 2003: 74; Carling 2006: 7; Okojie et al. 2003). The monitoring problem is exacerbated by the diverging incentives of traffickers/exploiters and victims. The latter still retain some degree of agency and can therefore make decisions, such as whether to declare the full amount earned in a given day. In addition, victims tend to spend part of their time away from the direct control of traffickers, as in the case of sex workers having encounters with clients. Moreover, offenders cannot turn to formal enforcement agencies to solve disputes, ensure compliance and enforce contracts (Reuter 1985; Campana and Varese 2013). In the case of transnational human trafficking, operations span a number of different countries, often far apart, and participants may be subject to restrictions on their freedom of movement (e.g. because of visa requirements, current police investigations or previous convictions). The very nature of human trafficking creates an organisational problem that has a direct impact on the "trafficking capacity" of the criminal organisations involved.

A device that is often used to reduce monitoring costs in other contexts is trust; however, trust tends to be in short supply in the underworld (Campana and Varese 2013). Participants in trafficking operations are no exception, as is revealed by the following phone conversation (concerning the purchase of fake travel documents) which was wiretapped by the police during the investigation under consideration (see next Section for details):

Individual 1: I know that you want the money beforehand, but the person who has introduced me to you [...] has told me that he paid after you gave him the visa.

Individual 2: No, this is wrong. I want the money first [...].

Individual 1: So you don't do anything without the money?

Individual 2: Yes. I don't want to have debts. I want the money first. Some people say they will pay, but in the end they don't.

Individual 1: I am different.

Individual 2: I know. But my associates always take the money before doing anything [...]. We want the money first... If we fail to get you the visa, we will return the money.

Individual 1: Why don't we do it this way? I will pay you when I see the visa.

Individual 2: No, no.

(TrNA 2007: 900)

Both parties in this transaction show some degree of mutual distrust, and neither is willing to pay the counterparty in advance. One strategy to overcome the trust problem could be to 
internalise the transaction, by integrating both parties into a single organisation. The exchange would then be supported by a formalised set of rules and by a recognised hierarchy.

As is clear from this example, the organisational dilemma that traffickers face (to internalise or to externalise their activities) is similar to that faced by legitimate entrepreneurs when deciding how to organise their business. This dilemma was compellingly explored by Ronald Coase in his seminal work The Nature of the Firm (1937: 388). Coase identifies two alternative methods of coordinating production: (a) through the price mechanism that underpins transactions on the market; and (b) through the decisions of an entrepreneur who directs production within a firm. Market and hierarchy can thus be regarded as two distinct ways of organising transactions (see also Williamson 2005). What, then, happens in the case of trafficking? Are trafficking operations highly internalised or are they externalised? ${ }^{4}$

Trafficking is indeed best understood as a process that consists of distinct and consecutive stages which can generally be identified as: (a) recruitment; (b) transportation; (c) exploitation. Recruitment refers to the acquisition of control over a victim by different means, including abduction, gross deception or payments to the victim's relatives. Recruitment usually takes place in the source country. Transportation refers to the movement of a victim from a source to a destination country. Exploitation is the final stage of trafficking operations, and usually takes place in the destination country. The key point here is that some stages may benefit from economies of scale more than others. For the transportation stage, an increase in the number of victims may greatly decrease the cost-per-victim associated with setting up and running the informal infrastructure (made up of safe houses and local agents), as well as acquiring the relevant knowledge about visas, trafficking routes and counter-trafficking measures. At the same time, monitoring costs tend to be lower in this stage as the time during which victims are involved is shorter. The exploitation stage, on the other hand, may present severe limits to the development of economies of scale, as victims have to be monitored closely and individually for lengthy periods. The extent of monitoring is often very large, and includes acquiring constant and reliable information on the victim's whereabouts and the earnings generated from each transaction between a single victim and her clients. For high-capacity trafficking networks, the costs incurred during the exploitation stage may be considerable.

Thus, for high-capacity networks we can derive the following hypotheses:

(a) The establishment of a centralised fund would not be feasible given the large monitoring costs that this would entail, and thus we would not observe a centralised system of payments 
for salaries and expenses. As a consequence, we should observe an overall low level of internalisation of trafficking activities;

(b) We should observe a tendency towards a separation of the transportation activities and the exploitation activities, so as to benefit from the economies of scale associated with the former and in order to decrease the overall monitoring costs;

(c) As the benefits from economies of scale will be relatively greater during the transportation stage rather than the exploitation stage, we should observe a relatively higher level of centralisation in relation to the former when compared to the latter.

I will now turn to an in-depth analysis of a high-capacity trafficking ring to empirically test these hypotheses.

\section{Data and methods}

This paper focuses on Nigerian trafficking for the purpose of sexual exploitation. To move beyond the anecdotal evidence and empirically explore how coordination is achieved, it offers an in-depth analysis of the operations of a major trafficking ring active between Nigeria (Benin City, Edo State) and Europe (mostly Italy and the Netherlands, and to a lesser extent Spain, the UK and France). The case under consideration appears to be in line with the general pattern displayed by Nigerian trafficking to Europe: Italy and the Netherlands are in fact commonly identified as the main destination countries for Nigerian trafficking (Okoije et al. 2003: 47-49). Several sources also indicate that Nigerian trafficking to Italy is often connected to prostitution (Carling 2006: 25; also Prina 2003 and Okoije et al. 2003). The centrality of Edo State, and its capital Benin City, in the recruitment for prostitution is also well established (Prina 2003; Okoije et al. 2003). ${ }^{5}$

The data for this paper comes from a systematic analysis of two indictments, totalling some 600 pages, that were prepared by the Italian authorities at the end of an investigation launched in 2006 (the documents are referred to in the text of this paper as TrNA 2007 and TrNA 2009). The Europe-wide investigation was first launched by the Dutch police following the disappearance of around 140 Nigerian women from refugee centres in the Netherlands between 2005 and 2006 (Michaud 2009). Some of the women were later found working in Italy as prostitutes. The files I collected were prepared by the Italian Prosecutor's Office and include 
transcripts of phone conversations and text messages wiretapped by the police, details of a number of trafficking journeys between Africa and Europe, and background information about the offenders against whom an arrest warrant was issued. This paper focuses on trafficking journeys with Italy as their final destination.

Based on a systematic content analysis of the court files, I was able to build three novel datasets. The first is a two-mode network dataset (actor-by-event) that records all the individuals associated, in any capacity, with each trafficking event. For the purpose of this paper, a trafficking event is defined as a discrete entity that includes activities carried out during a limited period of time with reference to the transportation and the exploitation of one or more victims. A typical trafficking event relates to activities from the start of the journey in West Africa to the delivery of the victim and her initial exploitation in the destination country (unfortunately the evidence on recruitment is rather unsatisfactory for a reliable quantitative analysis). To further minimise potential biases and increase the validity of the data, the dataset is based only on the evidence collected during two months of enhanced surveillance by the police, for which I have complete information about the activities of the trafficking ring (between 28 May and 28 July 2007). This dataset includes 16 journeys and 58 individuals associated with those journeys. In network terminology, this is often called an 'affiliation network' (see Borgatti and Halgin 2011): only ties between individuals and events are recorded, and each tie represents the participation of given individuals in a given event. This paper is the first to use a two-mode matrix to explore human trafficking networks.

Affiliation networks can be converted into networks of co-affiliation, for example by creating a new matrix that records whether two individuals have jointly attended the same event. The resulting dataset is a one-mode network (actor-by-actor), with the same actors listed on both rows and columns. This matrix allows the pattern of relationships among actors to be analysed. For instance, in this second dataset, each tie (link) records the co-participation of two offenders in a given trafficking event. Ties have no direction, but they are valued: the more events two offenders jointly took part in, the higher the value of their tie ${ }^{6}$. A number of network analysis techniques were then applied in order to explore the structure of the trafficking ring. Other scholars have utilised this type of evidence and techniques when studying human trafficking rings (Cockbain et al. 2011; Mancuso 2014; Morselli and Savoie-Gargiso 2014) and organised crime groups more generally (e.g. Natarajan 2006; Malm et al. 2011; Bright et al. 2012; Campana 2011; Campana and Varese 2012 and 2013; Varese 2013; Gill et al. 2014; Calderoni 2014; Mackenzie and Davis 2014). Finally, a third dataset was created to record characteristics of the actors such as gender, nationality and place of residence. 
To estimate the drivers of coordination I have applied a regression technique specific to network data, namely QAP regression (Quadratic Assignment Procedure: Krackhardt 1987 and 1988; Dekker et al. 2007). Network data is relational by definition, and therefore violates the assumption of non-independence of observations postulated by standard regression models (Krackhardt, 1988: 360). QAP techniques offer a solution to the problem of auto-correlation, or non-independence of observations, and provide a method for testing hypotheses based on a permutation-based nonparametric test of dependence between two or more square matrices of the same size (Dekker et al., 2007: 565-566). The approach is similar to that of multiple linear regression, and its results can be interpreted in the same way. The method adopted for the permutation is Double Semi-Partialing (Dekker et al. 2007).

Throughout the paper, I use the term "network" in an instrumental way to indicate a joint set of actors and relationships among them and not to indicate a specific form of organisation (as in Powell 1990).

\section{The structure of the trafficking network}

The overall number of actors involved in the 16 trafficking events is 58, of which 25 are offenders and 33 are victims. On average, each event involved 5.3 offenders. Victims were usually flown into Europe from various African airports using top-level carriers, including KLM, Air France and Iberia (TrNa 2009). Based on pictures secretly taken by police officers at Milan and Naples airports, and included in the court files, the victims dressed smartly during the journeys, often wearing business suits (TrNa 2009: 126-127; 156-157; 170-171). The number of victims transported in each journey ranged between 1 and 3 , with an average of 2.1 victims. The relatively small number of victims trafficked during each journey and the modus operandi adopted during the transportation phase sets this case clearly apart from the large-scale smuggling of migrants between, for example, Northern Africa and the southern coast of Italy.

The trafficking ring was fully operational well before the two-month monitoring period and would have continued its operations afterwards had the police not intervened. We can therefore estimate a yearly trafficking capacity based on the information available: everything else being equal, this capacity would be around 200 victims per year. It is therefore reasonable to consider the ring under scrutiny as an example of a 'high-capacity' trafficking network. This is clearly a high-capacity as regards to trafficking standards (and not smuggling standards): as a term of 
reference, in 2012 the overall number of Nigerian victims of trafficking identified in $23 \mathrm{EU}$ countries was 440; this figure was 501 the year before and 381 in 2010 (Eurostat 2014: 39).

Table 1 offers a summary of characteristics of the offenders involved in the trafficking network.

Table 1. Summary of characteristics of offenders involved

[INSERT TABLE 1 HERE]

Offenders include both men and women mostly based in Italy and West Africa. ${ }^{7}$ Despite being commonly referred to as "Nigerian trafficking", in reality the ring includes a number of different nationalities with a prominent presence of Ghanaians (28\%). The average age of offenders is relatively high (34 years): this is consistent with the idea that human trafficking is a businesslike enterprise and not some form of youth gang. Kinship does not appear to play a key role: only two pairs of offenders share a blood tie. Finally, there is no violence associated with the interactions among offenders.

Based on the content of the wiretapped conversations and other evidence included in the court files, I was also able to identify four main roles: management, resource acquisition, trolleys and madams. Management refers to individuals who are in a position to make decisions and are called in when problems arise. In addition, they give orders but do not receive them. Only three offenders are included in this group. Resource acquisition refers to individuals tasked with acquiring resources, such as plane tickets, forged documents and safe houses $32 \%$ of offenders) Trolley is the term usually used to refer to individuals tasked with escorting victims during the journey (Siegel and de Blank 2010): 20\% of offenders are associated with this role. Finally, 36\% of offenders are Madams, typically former prostitutes turned into traffickers. They are all female and based in Italy (this is consistent with Siegel and de Blank 2010; Mancuso 2014). Furthermore, I was able to manually assign each actor to a trafficking stage as it emerged from the content of the conversations wiretapped and other evidence included in the court file. To avoid bias, the analysis was restricted to transportation (16 offenders) and exploitation (9 offenders). Figure 1 offers a graphical representation of the overall network of offenders and victims.

Figure 1. The Nigerian trafficking network (All actors: offenders and victims) [FIGURE 1 HERE]

Each dot (node) in the figure represents an individual: offenders are plotted in grey and victims in white. The graph is generated using a force-directed algorithm that is based on the principle 
that nodes that are connected by a tie should be drawn near each other (Kamada and Kawai 1989). The size of each node indicates its degree centrality, i.e. the number of ties each individual exchanged with any other actor in the network. ${ }^{8}$ In this picture, it can be interpreted as the level of co-participation in trafficking events by each individual. Two offenders (\#1 and \#2) stand out as the most central players, and they are also independently classified as 'management'. A third offender (\#3) also appears to be fairly central. ${ }^{9}$ It is perhaps not surprising that victims tend to be rather peripheral in the network as they were mostly associated with only one trafficking event. Perhaps more interesting is that a large number of offenders are also peripheral. This suggests that there are a number of offenders who are not continuously involved in the activities of the ring. For instance, they co-participate in an activity with other offenders, and then they leave the network.

Let us explore this structure further. I set out to assess how trafficking activities are organised, and specifically whether they tend to be internalised or externalised. Network analysis offers a novel way to look at this issue. This approach - to my knowledge never applied to any criminal network - is based on the idea that, if operations are largely internalised, one should expect the same set of offenders to co-participate in a large number of events, if not all of them. This should be particularly the case for small organisations as these have a strong incentive to maximise the use of their workforce. In contrast, if operations are largely externalised, one should expect offenders to co-participate in a smaller number of events as each individual is likely to have been contracted on an ad hoc basis. The first scenario is consistent with the 'firm' model, while the latter is closer to the 'market' model (Coase 1937). If the nature of the events is kept constant, as in the case under scrutiny, one can assume that the type of skills and expertise required are also largely constant across all events. We can thus use the pattern of coparticipation in the 16 trafficking events to empirically reconstruct the organisational principle underlying the network's activities (Figure 2).

Figure 2. Co-participation of offenders in trafficking events [HERE FIGURE 2]

Out of 25 offenders, only 12 were jointly involved in two trafficking events. Co-participation drops significantly as the number of events increases. Only four offenders were jointly involved in five events; three offenders were jointly involved in $50 \%$ of the events, and two offenders were jointly involved in $75 \%$ of the events. The evidence suggests that traffickers may have a tendency to externalise activities rather than internalise them. In Coasian terms, this human trafficking network is organised around a market-based coordination mechanism more than a 
'firm'. This is also confirmed by the fact that there is no evidence of a common fund shared by all traffickers. However, even in relatively flat and fragmented networks, there is still a need for coordination - as demonstrated by the presence of a relatively small group of traffickers involved in a large number of events. What are the determinants of this coordination? More broadly, what explains the structure observed?

\section{Explaining coordination among traffickers}

In the network under scrutiny, each tie between two offenders indicates co-participation in a trafficking event. Arguably, this measure can be regarded as a proxy for coordination: the higher the number of ties exchanged, the higher the level of coordination between two offenders (coordination can also be interpreted as a measure of co-offending). Therefore, we can explain coordination by explaining tie-formation among offenders. The matrix recording tie-formation is the dependent network variable for the regression model presented in Table 2.10 The same model includes a number of additional matrices as independent network variables. These matrices record whether two offenders share: the same place of residence, the same nationality, a kin-tie, or the same role in the trafficking ring, and whether they are both involved in the transportation stage (as opposed to exploitation). Finally, the model also includes an independent network variable that records the age difference among each pair of offenders (i.e. a proxy for difference in seniority).

Table 2. Determinants of coordination among offenders

[Table 2 HERE]

Although not statistically significant, sharing the same place of residence has a negative effect on coordination. This is expected as the trafficking ring is essentially involved in transnational illegal trade. What is more interesting is the effect of nationality: coordination is more likely to take place across different nationalities rather than to occur within the same nationality. If we take nationality to be a proxy for ethnicity, this finding possibly speaks against a widely held belief. There is a positive effect of kinship on coordination, but this effect is rather small and not statistically significant. In addition, only two dyads of next-of-kin are present in the networks. More than being run along ethnic or family lines, the trafficking ring under scrutiny seems to be a fully-fledged business operation.

Alongside nationality, the two main determinants of coordination are the role performed by each offender and the main trafficking stage. Sharing the same role has a negative impact on 
coordination. Put simply, coordination is more likely to emerge across roles rather than within roles; for instance, 'trolleys' coordinate more with managers and madams rather than among each other. Similarly, madams tend to coordinate more with managers and trolleys than among one other. This is consistent with the adoption of a model based on the division of labour and role specialisation.

Finally, the offenders involved in the transportation stage tend to coordinate more when compared to those involved in the exploitation. This finding confirms our theoretical expectations regarding the functioning of high-capacity networks. It also indicates that madams tend to be independent of each other, and tend not to extend their control over the whole trafficking process. An analysis of the density of the ties within and across the stages shows that exploiters (i.e. madams) have a very low level of intra-group density, that is almost zero (0.16). Transporters, on the contrary, record the highest level (1.06).11

These quantitative findings are supported by the content of the phone conversations that were wiretapped. The following phone call, for example, was exchanged during the delivery of a victim to a madam in the Italian city of Turin:

Trafficker 1: It is better not to show her [the madam] the girl until she has paid the money. You first have to get the money, try to get it right.

Trafficker 2: She is alone.

Trafficker 1: I know. If she wants the bingo [the girl], she has to pay first. Maybe she does not have the money with her. Tell her she has to pay first, try not to make the mistake of showing the girl first. When she sees the girl, she will try to create trouble. Try not to get there. You have to get the money first. (TrNA 2009: 112)

The payment discussed in the wiretap is not the "price" of the victim, but the fee charged for escorting her from the origin to the destination country. Transporters expect to be paid (in full) at the moment of delivery. This indicates a separation between transportation and exploitation. Transporters and madams also show an acute trust problem; to overcome it, they rely on simultaneous transactions (TrNA 2009: 112-116).

In sum, madams tend to be independent of each other as well as independent of transporters. ${ }^{12}$ Transporters act as service providers contracted by the madams. They supply a specific service: the escorted transfer of people from an origin to a destination point. They charge a fee for this service. Details of the final destination of a trafficking journey are supplied by the madams before the beginning of the journey, to avoid an extra cost being imposed on the transporters 
(TrNA 2007; 2009). The sketchy evidence available indicates that the madams are also involved in the recruitment, but that the transporters are not (TrNA 2007; 2009).

Keeping transportation and exploitation separate decreases the overall monitoring costs. However, madams are still left with a principal-agent problem when exploiting their victims, often for extended periods of time. Besides under-reporting their daily income, victims may have opportunities to build bridges with the broader society through, for example, social workers or clients. This, in turn, will increase the costs borne by madams as well as their risk of being reported to the police. The files offer evidence of five distinct strategies that madams adopted to monitor victims and increase their compliance: the use of force (very limited in the case under scrutiny); the alignment of incentives between madams and victims' families ${ }^{13}$; hostage-taking strategies whereby a victim's family members based in Nigeria can be used as a target for retaliation; contracts and voodoo rituals ${ }^{14}$; and finally direct monitoring (e.g. sharing the same house). A key point that emerges from the evidence is the following: when a person was sent to threaten a victim's family in Benin City, it was the madam who gave him orders on the phone, and also paid for his service. There was no involvement of any transporter (TrNA 2007: 810).

\section{Conclusions and policy implications}

The literature on human trafficking has so far largely overlooked the costs associated with this type of illicit trade. Traffickers are often described as invariably successful individuals who are able to benefit from large economies of scale. This paper has proposed a different view. It has argued that the costs associated with human trafficking, in particular the monitoring costs, may be significant, and that the economies of scale are limited. It has also argued that it is only by obtaining a good understanding of the role played by costs and constraints that we can make sense of the organisational structures adopted by traffickers.

This paper has relied on novel datasets manually coded from court files relate to a major Nigerian trafficking ring, and analysed by applying a number of network analysis techniques. It has been the first to look at the co-participation in trafficking events, and to use this evidence to explore coordination among offenders. The network under scrutiny does not appear to be a unified organisation, but rather a collection of largely independent actors. There is no indication of a common shared fund; in addition, activities appear to be largely externalised. This is contrary to what the Salt and Stein model (1997) predicts. Moreover, there is a tendency 
towards a separation between the transportation and the exploitation stage. This is a crucial organisational arrangement that allows for higher trafficking capacity.

Some level of centralisation is, indeed, present and is generated by a core group of three offenders. However, central coordination is mostly confined within a single stage, namely transportation. The exploitation stage is populated by actors with a very large degree of independence. These are the so-called 'madams', and they tend not to coordinate among each other. This work has also been the first to explain the structure of a trafficking ring through the application of a regression technique specific to network data. Contrary to a widely held belief, the trafficking ring observed was not run along ethnic lines, and the effect of kinship also turned out to be rather tenuous. The evidence suggests the adoption by the traffickers of a more sophisticated model, based on the division of labour and role specialisation.

Moreover, there is no evidence of a global mafia that is able to internalise trafficking activities across continents, or to provide services like dispute settlement and contract enforcement in every stage of the process (contrary to what some authors have claimed). There are indications of racketeering activities in areas controlled by local mafia groups, e.g. the Camorra in Naples, but these activities are orthogonal to the trafficking business (TrNA 2007: 678). In these areas, a local mafia group imposes a fee for the use of the pavement where sex workers operate. Analytically speaking, this is similar to a tax levied by a government. However, there is no evidence of any involvement by these local mafia groups in the prostitution activities or in any other trafficking activities. The job of trafficker and that of racketeer remain clearly distinct.

Finally, this study suggests some policy implications to better combat human trafficking. Firstly, there is a widely held belief that the key players in criminal networks are those who score highly on some centrality measures, for instance, the number of ties they exchange. In the network under scrutiny, these would be the core group of three offenders. This group is undeniably important as it generates coordination; however, this coordination mostly extends to transportation activities only. On the contrary, madams are peripheral in the network, but not necessarily less important. If anything, the opposite is true: it is the madams who generate the demand for the trafficking services that are then provided by the transporters (TrNA 2007 and 2009; more generally see also Siegel 2012; Siegel and de Blank 2010; and Mancuso 2014). In other words, the transporters are contracted out by the exploiters. Madams appear peripheral because they are typically independent of the transporters and of each other. Therefore, not only is the presence of ties an important feature of criminal networks, but also their absence. In order to develop effective long-term policies to tackle these networks, it is 
crucial to identify and fully understand the mechanisms that have generated such structures. More generally, there is a rather striking parallel between how illegal trafficking operations are organised in this case and how legal deportations are organised in many states. Transporters and private security companies both act as contractors for, respectively, madams and governments. Analytically speaking, they both supply the same service and charge a fee for it. ${ }^{15}$

This analogy relates to a second point: too often policy-makers and scholars alike are carried away by the 'transnational mantra' that is the idea that phenomena that present elements of transnationality are invariably best fought transnationally. The analysis presented in this paper suggests that the best approach may not be a transitional one after all, but a domestic one. One way to combat the trafficking ring under scrutiny would be to target the core group of three offenders. However, they tend to be highly mobile and often based outside the European Union, which would imply a wholly transnational approach based on a potentially difficult judicial cooperation with institutionally weak countries. In addition, it is possible that these offenders could be easily replaced since the demand for their services is generated by the madams. Alternatively, we could adopt a more domestic-oriented approach and shift our focus to the madams. The evidence shows that madams tend be based in Western Europe and are highly embedded in their communities. In line with the view expressed by Turner and Kelly (2009), it seems sensible to engage with ethnic communities in the destination countries. This would not only identify the victims of trafficking, but also help to challenge the legitimacy of madams by offering viable alternatives to sex workers when they finally exit an exploitative situation and before they decide to turn into madams.

\section{Funding}

This work was supported by the European Union under the FP7 Framework Programme (Fiducia Project, Grant Agreement 290563).

\section{Acknowledgements}

I am very grateful to Ben Bradford, Julian Roberts, James Hollway and Federico Varese for their comments on an earlier version of the paper. I am also grateful to audiences at Nuffield College Oxford (11 June 2014), at the Conference on Organised Crime and Its Prosecution (School of Law, University of Manchester, 4-5 July 2014), at the European Society of Criminology Conference (Prague, 10-13 September 2014), at the Conference on Markets and Illegality (Max Planck Institute, Cologne, 5-6 February 2015), at the Department of Sociology, University of 
Oxford (9 February 2015) and at Institute of Criminology, University of Cambridge (27 February 2015).

\section{References}

\section{$\underline{\text { Court files }}$}

TrNA (2007). Tribunale di Napoli. Ordinanza del Giudice delle Indagini Preliminari, N. 19963/07. TrNA (2009). Tribunale di Napoli. Ordinanza di Applicazione Misure Cautelari, N. 164/096.

\section{Books and Articles}

Aronowitz, A. (2001), 'Smuggling and trafficking in human beings: the phenomenon, the markets that drive it and the organisations that promote it', European Journal on Criminal Policy and Research, 9(2): 163-195.

Aronowitz, A. (2009). Human Trafficking, Human Misery. The Global Trade in Human Beings. Westport (CT): Praeger.

Aronowitz A., Theuermann G., and Tyurykanova E. (2010), Analysing the business model of trafficking in human beings to better prevent the crime. Vienna: OCSE.

Borgatti S. P., and Halgin D. S. (2011). 'Analyzing Affiliation Networks', in Scott J. and P. J. Carrington, eds, The Sage Handbook of Social Network Analysis. London: Sage.

Bright, D. A., Hughes, C. E., and Chalmers, J. (2012), 'Illuminating dark networks: a social network analysis of an Australian drug trafficking syndicate', Crime, law and social change, 57(2): 151-176.

Calderoni, F. (2014), 'Identifying Mafia Bosses from Meeting Attendance' in A. J. Masys, Networks and Network Analysis for Defence and Security, Cham (Zurich): Springer International Publishing, 27-78.

Caldwell, G., Galster S., Kanics J. , and Steinzor N. (1999). 'Capitalizing on Transition Economies: The Role of Russian Mafiya in Trafficking Women for Forced Prostitution'. In P. Williams (ed.), Illegal Immigration and Commercial Sex. A New Slave Trade, London: Frank Cass, 42-73.

Campana P. (2011). 'Eavesdropping on the Mob: the functional diversification of Mafia activities across territories'. European Journal of Criminology, 8(3): 213-228.

Campana P., and Varese F. (2012). 'Listening to the wire: criteria and techniques for the quantitative analysis of phone intercepts'. Trends in organized crime, 15(1): 13-30.

Campana P. and Varese F. (2013). 'Cooperation in criminal organizations: Kinship and violence as credible commitments', Rationality and society, 25(3), 263-289. 
Carling J. (2006), Migration, Human Smuggling and Trafficking from Nigeria to Europe. Geneva: IOM.

Coase, R. H. (1937), ‘The nature of the firm', Economica, 4(16): 386-405.

Cockbain, E., Brayley, H., and Laycock, G. (2011). 'Exploring internal child sex trafficking networks using social network analysis'. Policing, 5(2): 144-157

Danailova-Trainor, G. and Laczko, F. (2010). Trafficking in persons and development: towards greater policy coherence. International Migration, 48(4), 38-83.

Dekker, D., Krackhardt, D., and Snijders, T. A. (2007). 'Sensitivity of MRQAP tests to collinearity and autocorrelation conditions'. Psychometrika, 72(4), 563-581

Eurostat (2014), Trafficking in human beings. Luxembourg: European Union.

Kamada, T., and Kawai, S. (1989). 'An algorithm for drawing general undirected graphs'. Information processing letters, 31(1), 7-15.

Gill, P, Jeongyoon L, Rethemeyer K. R., Horgan J, and Asal V. (2014), 'Lethal Connections: The Determinants of Network Connections in the Provisional Irish Republican Army, 19701998', International Interactions, 40:1, 52-78.

Gozdziak, E. M., and Collett, E. A. (2005), 'Research on human trafficking in North America: A review of the literature', International Migration, 43(1-2): 99-128.

Hales, L., and Gelsthorpe, L. (2012). The Criminalisation of Migrant Women. Institute of Criminology: University of Cambridge, UK.

Hoyle C., M. Bosworth, and Dempsey M. (2011). 'Labelling the Victims of Sex Trafficking: Exploring the Borderland between Rhetoric and Reality'. Social \& Legal Studies 20: 313-329.

Hyland, K. E. (2001), 'Protecting human victims of trafficking: An American framework', Berkeley Women's Law Journal, 16: 29-71.

Içduygu, A., and Toktas, S. (2002). 'How do smuggling and trafficking operate via irregular border crossings in the Middle East? Evidence from fieldwork in Turkey'. International Migration, 40(6): $25-54$

Kandathil, R. (2005), 'Global sex trafficking and the Trafficking Victims Protection Act of 2000: Legislative responses to the problem of modern slavery’, Mich. J. Gender \& L., 12, 87-118. .

Kleemans, E. (2011). Human smuggling and human trafficking. In M. Tonry (ed.), Oxford Handbook on Crime and Public Policy, Oxford: Oxford University Press, pp. 409-427 
Kleemans, E. R., and Smit, M. (2014). Human smuggling, human trafficking, and exploitation in the sex industry. In L. Paoli (ed), The Oxford Handbook of Organized Crime, Oxford: Oxford University Press, 381-401.

Krackhardt, D (1987). 'QAP partialling as a test of spuriousness'. Social Networks, 9(2), 171-186

Krackhardt, D (1988). 'Predicting with networks: nonparametric multiple regression analysis of dyadic data', Social Networks, 10(4), 359-381.

Mackenzie, S., and Davis, T. (2014). 'Temple Looting in Cambodia Anatomy of a Statue Trafficking Network'. British Journal of Criminology, online first.

Mai N. (2010). Migrant Workers in the UK Sex Industry. Final Report. Institute for the Study of European Transformation. London Metropolitan University.

Malm A., Bichler, G., and Nash R. (2011), 'Co-offending between criminal enterprise groups', Global Crime, 12(2): 112-128

Mancuso, M. (2014). 'Not all madams have a central role: analysis of a Nigerian sex trafficking network', Trends in Organized Crime, 17(1-2): 66-88.

Michaud E. (2009), 'Dutch tribunal to rule on human trafficking case', Radio Netherland Worldwide, 3/XII.

Morselli, C., and Savoie-Gargiso, I. (2014), 'Coercion, control, and cooperation in a prostitution ring'.The Annals of the American Academy of Political and Social Science, 653(1): 247-265.

Natarajan, M. (2006), 'Understanding the structure of a large heroin distribution network: a quantitative analysis of qualitative data'. Journal of Quantitative Criminology, 22(2): 171-192.

Okojie C. E. E., Okoji O., Eghapona K., Vincent-Osaghae G., and Kalu V. (2003).,Trafficking of Nigerian Girls to Italy. Tunin: UNICRI.

Powell, W. W. (1990), 'Neither Market nor Hierarchy', Research in Organizational Behavior, 12, 295-336.

Prina F. (2003), Trafficking of Nigerian girls to Italy. Trade and exploitation of minors and young Nigerian women for prostitution in Italy. Turin: UNICRI.

Reuter P. (1985), The Organization of Illegal Markets: an Economic Analysis. Washington, DC: National Institute of Justice.

Salt, J. (2000). 'Trafficking and human smuggling: A European perspective'. International Migration 38(3): 31-56. 
Salt, J. and Stein, J. (1997), 'Migration as a business: the case of trafficking', International migration, 35(4): 467-494.

Selvatici, F. (2013), 'Giustizia: Rimpatrio dei detenuti stranieri? Per ognuno il costo va dai 10 ai 20 mila euro', la Repubblica, 21/VIII.

Shannon, S. (1999). 'Prostitution and the Mafia: The Involvement of the Organized Crime in the Global Sex Trade'. In P. Williams (ed.), Illegal Immigration and Commercial Sex. A New Slave Trade. London: Frank Cass, 119-144.

Shelley, L. (2007). 'Human trafficking as a form of transnational crime'. In M. Lee (ed). Human Trafficking. Portland: Willan Publishing.

Shelley, L. (2010), 'Human Trafficking: A Global Perspective', Cambridge, UK: Cambridge University Press.

Siegel, D. (2012), 'Mobility of sex workers in European cities', European Journal on Criminal Policy and Research, 18(3), 255-268.

Siegel, D., and de Blank, S. (2010), 'Women who traffic women: the role of women in human trafficking networks - Dutch cases', Global Crime, 11(4), 436-447.

Triandafyllidou, A., and Maroukis, T. (2012), Migrant Smuggling: Irregular Migration from Asia and Africa to Europe. Basingstoke: Palgrave Macmillan.

Turner, J., and Kelly, L. (2009). "Trade Secrets Intersections between Diasporas and Crime Groups in the Constitution of the Human Trafficking Chain”. British Journal of Criminology, 49(2), 184-201

U.S. Department of State (2001), Trafficking in persons report. Washington, DC: Department of State.

Varese, F. (2013), 'The structure and the content of criminal connections: the Russian Mafia in Italy', European Sociological Review, 29(5), 899-909.

Vayrynen, R. (2003). Illegal immigration, human trafficking, and organized crime. World Institute for Development Economics Research, UNU-WIDER, Discussion Paper 72.

Wasserman S., and Faust K. (1994), Social Network Analysis. Cambridge: Cambridge University Press.

Wheaton, E. M., Schauer, E. J., and Galli, T. V. (2010). 'Economics of human trafficking'. International Migration, 48(4): 114-141.

WHO (2012). Human trafficking. Geneva: World Health Organization. 
Williamson, O. E. (2005), 'The economics of governance', American Economic Review, 1-18. 
Table 1. Summary of characteristics of offenders involved

\begin{tabular}{lll}
\hline Variable & & $\mathrm{N}$ \\
\hline Gender & Male & 15 \\
& Female & 10 \\
\hline Place of residence & Italy & 15 \\
& Africa & 6 \\
& Other EU country & 4 \\
\hline Nationality & Nigerian & 15 \\
& Ghanaian & 7 \\
& Ivorian & 2 \\
\hline Age & Togolese & 1 \\
\hline Role & Average (Years) & 34 \\
& Management & 3 \\
& Resource Acquisition & 8 \\
\hline Siolence & 'Trolley' (Escorting) & 5 \\
\hline Kinship & 'Madam' & 9 \\
\hline & Transportation & 16 \\
& Exploitation & 9 \\
\hline & Yes & 4 \\
& No & 21 \\
\hline & No & 25 \\
\hline
\end{tabular}


Table 2. Determinants of coordination among offenders

\begin{tabular}{lcc}
\hline & \multicolumn{2}{c}{ Model 1 } \\
\hline Gender & \multicolumn{2}{c}{---} \\
Violence & -0.020 & $(0.117)$ \\
Residence & $-0.161^{* *}$ & $(0.102)$ \\
Nationality & 0.102 & $(0.024)$ \\
Age (difference) & 0.064 & $(0.360)$ \\
Kinship & $-0.207^{* *}$ & $(0.128)$ \\
Role & $0.267^{* *}$ & $(0.129)$ \\
Transportation & 0.000 & $(0.000)$ \\
Intercept & & \\
& & \\
Adj. R-square & 0.089 & \\
Model probability & 0.006 & \\
\hline
\end{tabular}

Note: QAP regression for network data. Dependent variable: Number of ties among offenders (ln). Standardized coefficients. Standard errors in brackets. ${ }^{* *}$ Significant at 0.05 level. 
Figure 1. The Nigerian trafficking ring (All actors: offenders and victims)

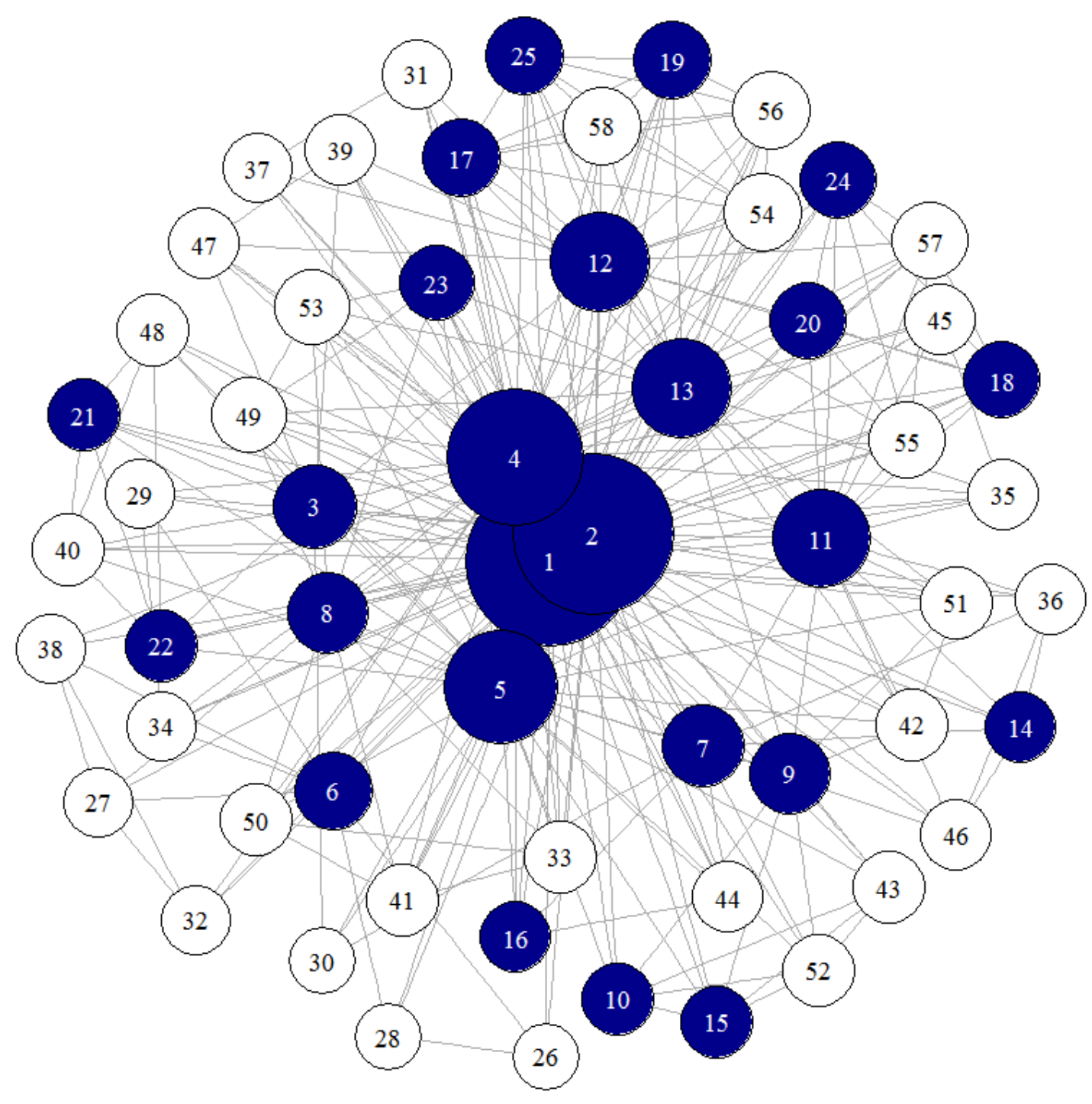

Note: Node colour is as follows: offenders are grey, victims are white. Size of a node indicates its degree centrality. The layout is based on the Kamada-Kawai algorithm. 
Figure 2. Co-participation of offenders in trafficking events

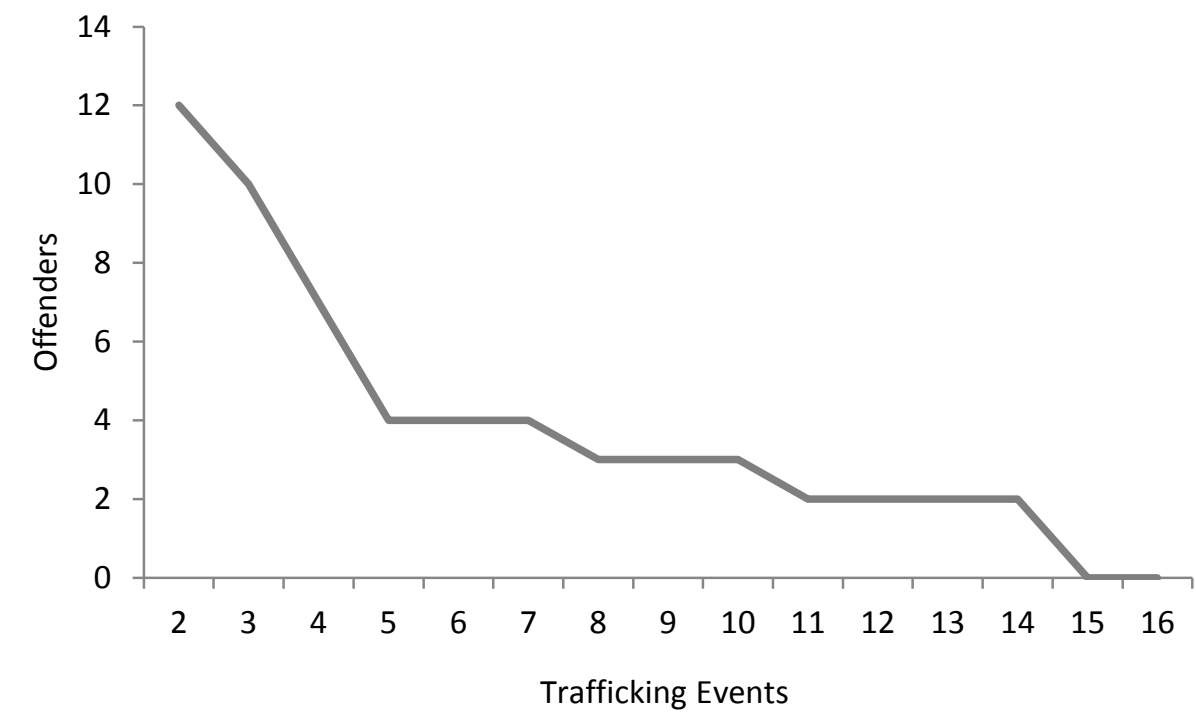




\section{ENDNOTES}

${ }^{1}$ See, among others, Gozdiak and Collett 2005; Danilova-Trinov and Laczko 2010; Mai 2010; Wheaton et al. 2010; Hoyle et al. 2011; Chin and Finckenauer 2012; Kleemans 2011; Kleemans and Smit 2014.

${ }^{2}$ For a discussion on trafficking, smuggling and their interplay with exploitation, see Kleemans 2011; Kleemans and Smit 2014

${ }^{3}$ The use of terminology in Aronowitz's work is slightly confusing. The large organisations included in the third category are described as being at the same time "horizontal" as well as governed by a centralised entity that controls all the activities (i.e. hierarchical).

${ }^{4}$ On the internalisation / externalisation of economic activities, see Williamson (2005: 6-7).

${ }^{5}$ Between 1999 and 2001, Italy deported to Nigeria around 800 women: 86\% of them came from Edo State (Carling 2006: 25).

6 The two-mode dataset was projected into a one-mode one without applying any normalisation (for details, see Borgatti and Halgin 2011).

7 The large number of offenders based in Italy relative to other European countries is explained by the nature of the data upon which the analysis is based (i.e. court files recording trafficking journeys with Italy as the final destination).

8 On degree centrality see, among others, Wasserman and Faust 1994: 178-180.

${ }^{9} \mathrm{~A}$ core group of three offenders was also identified by a core-periphery analysis.

${ }^{10}$ The dependent variable is a valued undirected network matrix (i.e. a continuous variable). After checking for normality, a natural logarithm transformation of the dependent variable was performed to make the estimations more robust.

11 Within group density is 0.44 .

${ }^{12}$ Occasionally, madams may set up joint-ventures to buy young women. In one instance, a victim was bought by three madams: one had $50 \%$ of the 'shares' while the other two each had $25 \%$. The agreement between the madams was stipulated before the beginning of the journey (TrNA 2007: 874).

${ }^{13}$ As families back home may receive a financial benefit from the work of their daughter, they also have an incentive to pressure their daughter to comply with the madam's orders (TrNA 2007: 897).

${ }^{14}$ Contracts are often 'signed' before a pastor who also performs certain voodoo rituals to sanction the agreement (TrNA 2007: 812). These rituals are usually performed in Nigeria before the journey begins (TrNA 2007: 742).

15 The fees charged by transporters are between $€ 10,000$ and $€ 12,000$. Deportations in Italy are not contracted out but are carried out internally by the national police. Nonetheless, the average cost for the state of a deportation from Italy to North Africa has been put at €10,000 (Selvatici 2013). 